\title{
Changes in physical fitness and body composition according to the physical activities of Korean adolescents
}

\author{
Minsoo Cho', Ji-Youn Kim ${ }^{2 *}$ \\ 'Liberal Arts College, Chungwoon University, Incheon, Korea \\ ${ }^{2}$ Exercise Rehabilitation Convergence Institute, Gachon University, Incheon, Korea
}

This study comparatively analyzed obesity, lean balance, and physical fitness related to growth and development in female middle school students to investigate the importance of regular physical activity on body composition and physical fitness in adolescence. The subjects were 31 elementary school students in grades 5-6 in Seoul, consisting of 16 students in the regularly active group and 15 students in the inactive group. Body composition and physical fitness factors were measured. Height, weight, body mass index (BMI), fat mass, and fat-free mass were measured using Inbody 3.0. Physical fitness factors such as muscle strength (grip strength), muscle endurance (situps), flexibility (body flexion), agility (side stepping), and lean balance (balancing with eyes closed), were measured as described herein. The results of comparing the two groups' obesity-related body composition, the weight $(P<0.001)$, body fat mass $(P<0.001), \mathrm{BMI}(P<0.002)$, and $\%$ body fat $(P<0.033)$ were sig-

\section{INTRODUCTION}

The age of 18 years or younger in the human life cycle is referred to as the juvenile period. This period is also critical to the development and growth of the body and is when various health-related habits are formed (Patton and Viner, 2007). In particular, the formation and establishment of healthy habits in the juvenile period leads to healthy lifestyles in adulthood and affects health both at the present time and in adulthood (Bélanger et al., 2015). Although studies have indicated that long-term sedentary behavior is harmful to health and that participation in regular physical activities is essential for health, normal growth, and physical development (Saunders et al., 2016), it has often been reported that Korean children and adolescents have improper habits such as little participation in physical activity and sedentary be- nificantly higher in the inactive group compared to the physically active group. Comparison of lean balance was there was a significant difference in muscle mass between the left and right $\operatorname{Arm}(P<0.001)$, left and right leg $(P<0.002)$ in the inactive group. comparing physical fitness between groups was trunk flexion $(P<0.001)$ and side stepping $(P<0.001)$ were higher in the physically active than the inactive group. This study found significant differences in weight, body fat, BMI, flexibility, and side stepping between the physically active and inactive groups, which may negatively affect health indicators related to adolescents' growth, development, and obesity. Therefore, attempts to promote physical activity in growing adolescents are crucial.

Keywords: Female students, Physical fitness, Body composition, Regular exercise

havior much of the time.

In fact, Heo et al. (2014) reported that smartphone and internet addiction in Korean children and adolescents is becoming a serious social problem, physical activity has decreased, and the morbid obesity rate has approximately doubled from $5.8 \%$ in 1998 to $9.7 \%$ in 2005 (Oh et al., 2008).

In addition, according to ICEF (International Consultants for Education and Fairs) Monitor (2014), various factors are considered to contribute to the deterioration of health in children and adolescents in Korea, but the most typical factors are Korea's competitive educational structure and prioritization of education. These factors affects physical activity, and as the grade level increases, PE class hours (that is, the only opportunity for students to be involved in moderate to vigorous physical activities during school hours) are being reduced (Lee and Cho, 2014). According

This is an Open Access article distributed under the terms of the Creative Commons Attribution Non-Commercial License (http://creativecommons.org/licenses/by-nc/4.0/) which permits unrestricted non-commercial use, distribution, and reproduction in any medium, provided the original work is properly cited.

${ }^{*}$ Corresponding author: Ji-Youn Kim (iD https://orcid.org/0000-0000-2325-1921 Exercise Rehabilitation Convergence Institute, Gachon University,

191 Hambangmoe-ro, Yeonsu-gu, Incheon 21936, Korea

Tel: +82-32-820-4442, Fax: +82-32-820-4449, E-mail: eve14jiyoun@naver.com

Received: September 11, 2017 / Accepted: October 16, 2017 
to an online survey of youth health behavior by the Korea Center for Disease Control and Prevention (KSDC, 2005, 2014), the percentage of students who did not participate in PE classes increased from $15.9 \%$ in 2005 to $27.4 \%$ in 2012 (Korea Centers for Disease Control and Prevention, 2005, 2014).

This decrease in physical activity causes severe problems such as decreased physical fitness, lack of exercise, stress, obesity, and adult illness, and even though the physique of youth has recently improved, physical fitness has, rather, decreased (Lee and Oh, 2012). This tendency has led to obesity in adolescence while social interest in health and physical fitness and obesity has heightened and demands for accurate analysis of the health status and fitness level of adolescents are increasing. However, most previous studies have focused on elementary school students, and the studies of youth health behaviors in middle and high school students are mostly conducted online. Furthermore, few studies have been conducted comparing adolescents performing various physical activities with adolescents who are not. In addition, considering the reality of Korean education that as adolescents' age, they spend more time studying, the importance of regular physical activity to adolescents' health care and growth should be emphasized in Korea. This study comparatively analyzed obesity, lean balance, and physical fitness related to growth and development in female middle school students to investigate the importance of regular physical activity on body composition and physical fitness in adolescence.

\section{MATERIALS AND METHODS}

\section{Survey subjects}

The subjects of this study and their parents were fully informed of the purpose of the study and consented in writing. The subjects were 31 elementary school students in grades 5-6 in Seoul, consisting of 16 students in the regularly active group and 15 students in the inactive group.

The regularly active group consisted of the members of Songpa-gu, Seoul, Korea municipal group residing in Seoul who performed regular physical activity at least twice a week for 4 years or more. The inactive group consisted of subjects who had not performed physical activity, such as after school activities and private institutes related to exercise, at all over the last year. The physical characteristics of the subjects are listed in Table 1.

\section{Measurement}

Body composition and physical fitness factors were measured. Height, weight, body mass index (BMI), fat mass, and fat-free
Table 1. Physical characteristic of subjects

\begin{tabular}{lcc}
\hline Characteristic & Physically active & Inactive \\
\hline Age $(\mathrm{yr})$ & $12.30 \pm 1.20$ & $12.70 \pm 0.90$ \\
Height $(\mathrm{cm})$ & $157.07 \pm 4.43$ & $158.67 \pm 3.68$ \\
Weight $(\mathrm{kg})$ & $47.75 \pm 3.58$ & $53.16 \pm 3.70$ \\
Experience exercising $(\mathrm{yr})$ & $4.70 \pm 1.55$ & 0 \\
\hline
\end{tabular}

Values are presented as mean \pm standard deviation.

mass were measured using Inbody 720 (Biospace Co., Seoul, Korea). Physical fitness factors such as muscle strength (grip strength), muscle endurance (situps), flexibility (body flexion), agility (side stepping), and lean balance (balancing with eyes closed), were measured as described herein.

\section{Measurement of body composition}

Inbody 720 (Biospace Co.), a body composition analyzer, was used to measure the changes in the body composition of the subjects. The subjects were asked to fast starting $12 \mathrm{hr}$ before measurement and measurement was performed from 10-12 a.m. Height, weight, BMI, fat mass, and body fat (\%), fat-free mass, and lean balance were analyzed using a results form.

\section{Measurement of physical fitness}

\section{Grip strength}

A dynamometer (TKK-5401, Takei, Tokyo, Japan) was used to measure grip strength. The subjects stood with both feet at shoulder width and maintained an angle of 15 degrees so that the torso and the arm (to be measured) did not touch each other, held the handle of the dynamometer with the second joints of their fingers, and pulled the handle while keeping their arms from shaking. The grip strength of both was measured, twice on each side, and the highest value was recorded in $\mathrm{kg}$ to the first decimal place.

\section{Situps}

The subjects lay on a mat and bent their knees about 140 degrees. The feet were flat on the floor, and then the upper body was raised until the elbows touched the knees. The number of repetitions made in $30 \mathrm{sec}$ was recorded.

\section{Trunkflexion}

Subjects sat barefoot with feet together by the side of a trunk flexion meter and bent the waist while extending both arms and folding their hands together and then pushed the measuring instrument slowly to the maximum extent. The knees were not to be bent at this time. After two repetitions, results were recorded in $\mathrm{cm}$ to the first decimal place. 
Table 2. Subjects' body composition

\begin{tabular}{lccc}
\hline Variable & PA group & Inactive group & $P$-value \\
\hline Height $(\mathrm{cm})$ & $157.07 \pm 4.43$ & $158.67 \pm 3.68$ & 0.288 \\
Weight $(\mathrm{kg})$ & $47.75 \pm 3.58$ & $53.16 \pm 3.70$ & $0.001^{*}$ \\
Body fat mass $(\mathrm{kg})$ & $11.85 \pm 2.73$ & $17.16 \pm 3.02$ & $0.001^{*}$ \\
Fat-free mass $(\mathrm{kg})$ & $35.50 \pm 3.67$ & $35.40 \pm 8.62$ & 0.829 \\
Body mass index $\left(\mathrm{kg} / \mathrm{m}^{2}\right)$ & $19.77 \pm 2.78$ & $22.68 \pm 3.79$ & $0.020^{*}$ \\
\% Body fat & $24.55 \pm 3.80$ & $27.58 \pm 7.67$ & $0.033^{*}$
\end{tabular}

Values are presented as mean \pm standard deviation.

$\mathrm{PA}$, physically active.

${ }^{*} P<0.05$

Table 3. Subjects' lean balance

\begin{tabular}{lccc}
\hline Variable & PA & Inactive & $P$-value \\
\hline Arm $(\mathrm{kg})$ & & & \\
Right & $1.4469 \pm 0.09$ & $1.4647 \pm 0.11$ & 0.563 \\
Left & $1.4506 \pm 0.10$ & $1.4433 \pm 0.10$ & 0.851 \\
$\quad$ Difference value & -0.038 & 0.0213 & $0.001^{*}$ \\
Trunk (kg) & $14.80 \pm 2.23$ & $14.3 \pm 3.88$ & 0.879 \\
Leg (kg) & & & \\
Right & $5.5750 \pm 0.40$ & $5.4487 \pm 0.49$ & 0.996 \\
Left & $5.5763 \pm 0.42$ & $5.3940 \pm 0.47$ & 0.921 \\
Difference value & -0.012 & 0.0547 & $0.002^{*}$ \\
\hline
\end{tabular}

Values are presented as mean \pm standard deviation.

$P A$, physically active.

${ }^{*} P<0.05$.

\section{Side stepping}

Parallel lines were drawn at a distance of $120 \mathrm{~cm}$ on the floor and the subjects stood on both feet, one foot on the left side and the other foot on the right side, from the center line. Once the right foot crossed the line to the right, they retuned to the initial position in a quick motion. They quickly stepped sideways again with their left feet without stepping on the line nor moving both feet at the same time, and the number of steps in $20 \mathrm{sec}$ was measured.

\section{Balancing with eyes closed}

Subjects stood barefoot on the floor with both hands on their waists. They bent one knee and raised it from the floor about 15 $\mathrm{cm}$. The time when one of the hands on the back dropped, when a part of the body touched the floor, and when the eyes were opened was measured in seconds to the first decimal point.

\section{Data analysis}

All data in this study was collected and analyzed using IBM SPSS Statistics ver. 20.0 (IBM Co., Armonk, NY, USA). The mean and standard deviation were calculated to present descriptive statistics for each group. An independent sample $t$-test was conduct-
Table 4. Subjects' physical fitness

\begin{tabular}{lccc}
\hline Variable & PA & Inactive & $P$-value \\
\hline Right grip (kg) & $19.92 \pm 2.95$ & $19.31 \pm 3.60$ & 0.401 \\
Left grip (kg) & $12.44 \pm 3.58$ & $12.84 \pm 3.55$ & 0.564 \\
Situps (reps/sec) & $23.00 \pm 4.64$ & $20.30 \pm 7.10$ & 0.102 \\
Trunk flexion (cm) & $15.89 \pm 3.65$ & $6.79 \pm 4.75^{*}$ & $0.001^{*}$ \\
Side stepping (reps/min) & $44.40 \pm 7.42$ & $32.00 \pm 3.57^{*}$ & $0.001^{*}$ \\
Balancing with eyes closed (sec) & $8.97 \pm 5.60$ & $8.44 \pm 4.98$ & 0.621 \\
\hline
\end{tabular}

Values are presented as mean \pm standard deviation.

$P A$, physically active.

${ }^{*} P<0.05$.

ed to verify the mean difference between the measurement items in each group and all statistical significance levels were set at 0.05 .

\section{RESULTS}

\section{Comparison of obese body composition}

The results of comparing the two groups' obesity-related body composition appear in Table 2. As shown in the table, the weight $(P<0.001)$, body fat mass $(P<0.001)$, BMI $(P<0.002)$, and $\%$ body fat $(P<0.033)$ were significantly higher in the inactive group compared to the physically active group.

\section{Comparison of lean balance}

The results of comparing the lean balance between groups appear in Table 3. There was no significant difference in the upper and lower limbs between the physically active and inactive groups. However, there was a significant difference in muscle mass between the left and right $\operatorname{Arm}(P<0.001)$, left and right $\operatorname{leg}(P<0.002)$ in the inactive group.

\section{Comparison of physical fitness}

The results of comparing physical fitness between groups appear in Table 4. Similar results were obtained for hand grip strength, situps, and balancing with eyes closed in the physically active group, while trunk flexion $(P<0.001)$ and side stepping $(P<0.001)$ were higher in the physically active than the inactive group.

\section{DISCUSSION}

This study was conducted in order to compare obesity, lean balance, and physical fitness related to growth and development in adolescents who perform regular physical activities for a long time with those of adolescents who do not perform any exercise at all.

Height $(\mathrm{cm})$, body weight $(\mathrm{kg})$, fat mass $(\mathrm{kg})$, fat-free mass $(\mathrm{kg})$, 
BMI $\left(\mathrm{kg} / \mathrm{m}^{2}\right)$, and body fat $(\%)$ were measured using a precision body composition analyzer called Inbody 720 (Biospace Co.), and left and right muscle mass and upper body muscle mass were measured for obesity and lean balance $(\mathrm{kg})$ by using an analysis results form.

As a result, it was found that all obesity variables were higher in the inactive group. There were significant differences in body weight $(P<0.001)$, body fat mass $(P<0.001)$, BMI $(P<0.002)$, and $\%$ body fat $(P<0.033)$.

Body fat $(\%)$ and BMI are representative indicators of obesity, and those with a body fat of over $30.0 \%$ and a BMI of over $25 \mathrm{~kg} / \mathrm{m}^{2}$ are considered obese. Both groups had less than $25.0 \%$ body fat and were not considered obese, but the body fat percentage was significantly higher in the inactive group. The results of this study are summarized as follows.

First, the relationship between physical activity and body fat mass is very strong, and the results of an 8-week combined walking-rope skipping exercise showed a decrease in body fat (Stoner et al., 2016) while physical activity was significantly associated with a normal weight (Faik et al., 2017).

Even through the inactive group in this study were not obese, it can be predicted that the risk of obesity will increase with long periods of inactivity.

The lean balance by comparing the left and right muscle mass is an important indicator for maintaining a well-balanced physique and growth in youth. In this study, the muscle mass of arms, legs, and trunk tended to be higher in the physically active group than in the inactive group, and regular physical activity had a positive effect on the development of muscle mass as shown in the study by Lee et al. (2017). There was no significant difference between left and right muscle mass in the physically active group or the inactive group A study of the muscle mass in the left and right limbs in high activity level and low activity level children (Wyszyńska et al., 2016) found no significant difference in the high activity level who were regularly trained, In addition, the left and right muscle mass was significantly higher in the high activity level.

That is why it is important to educate and encourage as much as possible to take various forms of physical activity, especially in children. Steinberg et al. (2013) confirmed benefits of activating children with the problem of excessive body mass. They proved that the weight management program for obese children improved their shape, stability, and the vestibular system, which reduced the likelihood of falls in the participants of the study. Similarly, recent studies of Schwanke et al. (2016) showed that a special program of exercise in overweight children led to positive changes in body posture, increased strength, and flexibility of muscles.

Despite the recent growth in the physique of adolescents, physical fitness has been decreasing. This tendency has led to obesity in adolescence as social interest in health and physical fitness and obesity has heightened. Meanwhile, there is increasing demand for an accurate understanding of the health status and fitness level of adolescents. According to data from Physical Activity Promotion System 2010, the number of students who received the lowest grade had increased by a factor of 1.7 in 2010 compared to 2009 (Lee and Oh, 2012). This study found that the physically active group showed a significant difference in trunk flexion $(P<0.001)$ and side stepping $(P<0.001)$ compared to the inactive group. Trunk flexion is an indicator of flexibility. Lo et al. (2017) reported that students performing more sports activities had significantly high flexibility compared to normal students who do not, and Monyeki et al. (2005) reported that the higher the BMI, the lower the flexibility. The results of those studies are consistent with the results of this study.

Additionally, side stepping ability was significantly lower in the inactive group. This difference was found more often in the inactive group in which side stepping did not show sufficient agility, equilibrium, or flexibility or the center of gravity was not stable, which may lead to a number of injuries due to trivial events such as stumbling over a stone (Kobayashi et al., 2014). Therefore, it is very important to improve agility through various physical activities because a decline in integrated coordination ability is more commonly found in children with decreased physical fitness and less exercise. In addition, regular physical activity has been reported to have a very positive effect on physical fitness. For example, there is a relationship between an increase in muscle mass in the upper and lower body and an improvement in physical fitness (Kim, 2015), and there is a significant relationship between physical activity, muscle strength, muscle mass, and bone density (Lindsay et al., 1992; Monyeki et al., 2012).

This study found significant differences in weight, body fat, BMI, flexibility, and side stepping between the physically active and inactive groups, which may negatively affect health indicators related to adolescents' growth, development, and obesity. Therefore, attempts to promote physical activity in growing adolescents are crucial.

\section{CONFLICT OF INTEREST}

No potential conflict of interest relevant to this article was reported. 


\section{REFERENCES}

Bélanger M, Sabiston CM, Barnett TA, O'Loughlin E, Ward S, Contreras G, O'Loughlin J. Number of years of participation in some, but not all, types of physical activity during adolescence predicts level of physical activity in adulthood: Results from a 13-year study. Int J Behav Nutr Phys Act 2015;12:76.

Faik A, Vanderhulst E, Rossem I, Devroey D. Influence of physical activity and interest for food and sciences versus weight disorders in children aged 8 to 18 years. J Prev Med Hyg 2017;58:E105-113.

Heo J, Oh J, Subramanian SV, Kim Y, Kawachi I. Addictive internet use among Korean adolescents: a national survey. PLoS One 2014;9:e87819.

ICEF Monitor. High performance, high pressure in South Korea's education system [Internet]. International Consultants for Education and Fairs Monitor; 2014 [cited 2017 Aug 20]. Available from: http://monitor.icef.com/2014/01/high-performance-high-pressure-in-south-koreas-education-system/.

Kim JS. The effect of yoga and pilates training on obesity indexes, muscle mass in each body part and physical fitness in male college students. J Korea Acad-Ind Cooper Soc 2015;16:5888-5896.

Kobayashi N, Matsumoto T, Takeuchi K, Mishima T, Yoshida T. Effect of stopping coordination exercises on the physical fitness and motor skills of children in the early years of primary school. J Teikyo Heisei Univ 2014;25:151-159.

Korea Centers for Disease Control and Prevention. Korea youth risk behavior, 2005. Cheongju: Korea Centers for Disease Control and Prevention; 2005.

Korea Centers for Disease Control and Prevention. Korea youth risk behavior, 2014. Cheongju: Korea Centers for Disease Control and Prevention; 2014.

Lee KC, Cho SM. The Korean national curriculum for physical education: a shift from edge to central subject. Phys Educ Sport Pedag 2014;19: $522-532$.

Lee KS, Lee JK, Yeun YR. Effects of a 10-day intensive health promotion program combining diet and physical activity on body composition, physical fitness, and blood factors of young adults: a randomized pilot study. Med Sci Monit 2017;23:1759-1767.

Lee YG, Oh SH. The relationship of obesity to health-related physical fitness of secondary school boys and girls a study on. Korean J Meas Eval Phys Educ Sport Sci 2012;14:29-43.
Lindsay R, Cosman F, Herrington BS, Himmelstein S. Bone mass and body composition in normal women. J Bone Miner Res 1992;7:55-63.

Lo KY, Wu MC, Tung SC, Hsieh CC, Yao HH, Ho CC. Association of school environment and after-school physical activity with health-related physical fitness among junior high school students in Taiwan. Int J Environ Res Public Health 2017 Jan 15;14(1). pii: E83. https://doi. org/10.3390/ijerph14010083.

Monyeki MA, Koppes LL, Kemper HC, Monyeki KD, Toriola AL, Pienaar AE, Twisk JW. Body composition and physical fitness of undernourished South African rural primary school children. Eur J Clin Nutr 2005;59:877-883.

Monyeki MA, Neetens R, Moss SJ, Twisk J. The relationship between body composition and physical fitness in 14 year old adolescents residing within the Tlokwe local municipality, South Africa: the PAHL study. BMC Public Health 2012;12:374.

Oh K, Jang MJ, Lee NY, Moon JS, Lee CG, Yoo MH, Kim YT. Prevalence and trends in obesity among Korean children and adolescents in 1997 and 2005. Korean J Pediatr 2008;51:950-955.

Patton GC, Viner R. Pubertal transitions in health. Lancet 2007;369:11301139.

Saunders TJ, Gray CE, Poitras VJ, Chaput JP, Janssen I, Katzmarzyk PT, Olds T, Connor Gorber S, Kho ME, Sampson M, Tremblay MS, Carson V. Combinations of physical activity, sedentary behaviour and sleep: relationships with health indicators in school-aged children and youth. Appl Physiol Nutr Metab 2016;41(6 Suppl 3):S283-293.

Schwanke NL, Pohl HH, Reuter CP, Borges TS, de Souza S, Burgos MS. Differences in body posture, strength and flexibility in schoolchildren with overweight and obesity: a quasi-experimental study. Man Ther 2016;22:138-144.

Steinberg N, Eliakim A, Pantanowitz M, Kohen-Raz R, Zeev A, Nemet D. The effect of a weight management program on postural balance in obese children. Eur J Pediatr 2013;172:1619-1626.

Stoner L, Rowlands D, Morrison A, Credeur D, Hamlin M, Gaffney K, Lambrick D, Matheson A. Efficacy of exercise intervention for weight loss in overweight and obese adolescents: meta-analysis and implications. Sports Med 2016;46:1737-1751.

Wyszyńska J, Podgórska-Bednarz J, Drzał-Grabiec J, Rachwał M, Baran J, Czenczek-Lewandowska E, Leszczak J, Mazur A. Analysis of relationship between the body mass composition and physical activity with body posture in children. Biomed Res Int 2016;2016:1851670. 